\title{
Condições bucais relacionadas com o estresse: uma revisão dos achados atuais
}

Buccal conditions related with the stress: a revision of the current discoveries

Maria Carmen Fontoura Nogueira da Cruz ${ }^{1}$, Vanessa Athayde Silva Braga ${ }^{2}$, João Gabriel Farah Garcia ${ }^{3}$, Fernanda Ferreira

Lopes ${ }^{4}$, Enara de Cássia Silva Maia ${ }^{5}$

\section{Resumo}

O desequilíbrio da harmonia entre o corpo e a mente é o que origina o desenvolvimento de doenças relacionadas ao estresse. Muitas patologias hoje estudadas têm íntima relação com o estresse, e estabelecer a relação estresse/doença é fundamental para conhecer e tratar algumas dessas patologias. Considerando-se a importância do tema para os alunos e profissionais da Odontologia, justifica-se a realização deste trabalho, com vista ao melhor entendimento a cerca do tema abordado e ao aprimoramento do diagnóstico das mesmas. Podemos sugerir que os aspectos psicossociais, em especial o estresse, têm sua participação na etiologia de algumas condições na cavidade bucal, atuando de forma conjunta com outros fatores, entretanto o papel do estresse nessas condições estudadas não está perfeitamente esclarecido. É necessário enfatizar que estas condições devem merecer atenção especial do cirurgiãodentista, que, por sua vez, faz parte de uma equipe multidisciplinar no atendimento do paciente, sendo necessário o encaminhamento do paciente portador de uma dessas condições associadas ao estresse a profissionais especializados, para uma terapia adjunta, podendo melhorar sobremaneira o resultado do tratamento odontológico.

Palavras-chave: Estresse, Mucosa bucal, Diagnóstico

\section{Abstract}

The unbalance between body and mind is what originates the development of diseases related to stress. A number of pathologies today studied has intimate relationship with stress. To establish the relationship between stress and disease is fundamental to know and to treat some of those pathologies. Considering the importance of the issue for dental students and professionals, it is justified the accomplishment of this work, with view to the best understanding about the approached theme and to the establishment of the its diagnosis. We can suggest that the psico-social aspects, especially stress, have their participation in the aetiology of some conditions in the oral cavity, acting in varied ways with other factors. However, the role of stress in those studied conditions is not perfectly understood. It is necessary to emphasize that these conditions should have the dentist's special attention and are part of a multidisciplinary team in the patient's attendance, being necessary the direction of the patient bearer of one of those conditions associated to stress to specialized professionals for an attached therapy.

Keywords: Stress, Buccal mucous membrane, Diagnosis
1 Professora-Adjunta do Programa de Pós-Graduação em Odontologia da Universidade Federal do Maranhão (UFMA), Doutora em Patologia Oral pela UFRN

${ }^{2}$ Cirurgiã-Dentista pela Universidade Federal do Maranhão (UFMA)

${ }^{3}$ Cirurgião-Dentista pela Universidade Federal do Maranhão (UFMA)

${ }^{4}$ Professora-Adjunta do Programa de Pós-Graduação em Odontologia da Universidade Federal do Maranhão (UFMA), Doutora em Patologia Oral pela UFRN

5 Cirurgiã-Dentista pela Universidade Federal do Maranhão (UFMA), especialista em Odontopediatria pela Universidade Federal do Rio de Janeiro (UFRJ)

Correspondência: Maria Carmen Fontoura Nogueira da Cruz

Endereço: Rua dos Rouxinóis, Condominio Alphaville, bloco I, apto. 102 - Renacença II CEP 65075-630 - São Luis - MA

E-mail: ma.carmen@uol.com.br

\section{Introdução}

A cavidade bucal é sede de uma diversidade de patologias, tanto de natureza local como sistêmica, de caráter multifatorial, no qual fatores psicossociais, como o estresse, representam um aspecto importante a ser considerado (SOTO ARAYA; ROJAS ALCAYAGARA; ESGUEP, 2004).

O estresse caracteriza-se como uma resposta do organismo a agressões de ordem física, psíquica e infecciosa capazes de perturbar seu equilíbrio. $O$ excesso do estresse, seja por grande intensidade ou duração do agente agressor, é capaz de produzir alterações a qualquer nível neuroendocrinoimune do organismo (SAINZ et al., 2001) estabelecendo, assim, a relação estresse/doença, o que explica a participação de fatores psíquicos no desenvolvimento de determinadas condições na mucosa bucal (ESGUEP et al., 1997).

Esse fato faz com que a Odontologia perceba a necessidade iminente de capacitar seus profissionais para detectar, reconhecer e instituir o tratamento adequado para as condições bucais associadas ao estresse (ELIAS et al., 2000).

Dessa forma, justifica-se a realização deste trabalho, a fim de revisar os vários aspectos da relação entre o estresse e a manifestação clínica de tais condições, com vista ao melhor entendimento a cerca do tema abordado e ao aprimoramento do diagnóstico das mesmas. 


\section{Condições bucais relacionadas com o estresse}

\section{Líquen Plano}

É uma doença mucocutânea, de caráter inflamatório e crônico (EDWARDS; KELSCH, 2002) que apresenta na cavidade bucal, uma diversidade de aspectos clínicos (SOTOARAYA; ROJAS ALCAYAGA; ESGUEP, 2004), acometendo a pele, a mucosa ou ambas, sendo que as apresentações bucais são mais frequentes do que as cutâneas e tendem a ser mais persistentes e mais resistentes ao tratamento (MOLLAOGLU, 2000). Tais manifestações podem representar os primeiros sinais da doença, bem como surgirem apenas após as aparições em pele (LOZADA-NUR, 2000). Sua etiopatogenia ainda é desconhecida, porém é possível que mecanismos imunológicos sejam importantes no início e na perpetuação do processo. O líquen plano bucal representa uma resposta imune mediada por células existentes na interação epitélio-linfócito dirigida contra antígenos dos ceratinócitos basais do epitélio, o que culmina na degeneração de sua camada basal (BASCONES-ILUNDAIN et al., 2006). É descrita uma possível associação do líquen plano bucal a fatores psicossomáticos como o estresse, a ansiedade, a depressão e outras alterações emocionais (HALACK et al., 2001). Sugerimos que a alteração no estado de ânimo do paciente pode produzir um impacto sobre o sistema neuroendócrino e influenciar a subpopulação linfocitária dos pacientes com líquen plano bucal (RÖDSTROM et al., 2001). É citada outra relação existente entre o líquen plano bucal com doenças sistêmicas crônicas, entre elas, o diabetes. Mas é sugerido que isso seja apenas uma coincidência, já que o líquen plano bucal é uma doença mucocutânea e que atinge pacientes com a faixa etária acima dos 40 anos, fato este também observado nos pacientes diabéticos (AMORIM et al., 2002).

Há uma diversidade de formas clínicas, sendo que a mais comum é a forma reticular que aparece como estrias brancas finas com aspecto rendilhado, conhecidas como estrias de Wickham, sendo normalmente este tipo assintomático e frequentemente descoberto incidentalmente durante um exame bucal de rotina. Já as formas atrófica, erosiva e bolhosa usualmente são associadas à sensação de ardência e, em alguns casos, podem causar dor severa nos pacientes. Sua natureza é crônica e persiste por longos períodos em alguns pacientes e poucos sofrem remissão completa (MOLLAOGLU, 2000).

\section{Língua Geográfica}

Condição caracterizada inicialmente pela presença de pequenas áreas de desceratinização e descamação das papilas filiformes. As áreas descamadas tornam-se vermelhas e apresentam um halo branco ou branco-amarelado. Esse aspecto persiste por um período variável, normaliza espontaneamente e aparece em outro lugar, configurando o aspecto migratório da lesão (REGEZI; SClUBBA, 2000). O diagnóstico é clínico e as lesões são patogno mônicas. Geralmente assintomática, pode provocar incômodo ou ardor nas zonas despapiladas, sobretudo com a ingestão de alimentos ácidos ou picantes. É importante não confundir esta situação com uma candidíase da língua, pois, muitas vezes, os pacientes são submetidos a tratamentos prolongados com antifúngicos, desnecessariamente (FEMIANO, 1995).

Ainda se desconhece a causa específica da condição, entretanto tem sido frequentemente influenciada por deficiências nutricionais, fatores emocionais, fatores irritantes (alimentos condimentados), fumo, álcool (GONZAGA et al., 1995) e seu aparecimento aumenta em aproximadamente $10 \%$ nas pessoas com psoríase cutânea (BOUQUOT, 1991).

\section{Síndrome da Boca Ardente}

Também conhecida como glossodínia, distesia bucal, glossopirose, glossalgia, estomatopirose, estomatodinia (DRAGE; ROGERS, 2003). É uma das mais intrigantes e complexas patologias envolvendo a cavidade bucal, uma vez que - paciente acometido não apresenta sinais clínicos (COSTA et al., 1999). Geralmente apresenta-se como tríade: dor na boca, alterações do paladar e alterações da salivação, sem lesão na mucosa bucal (GARCIA-MEDINA, 1994). A dor é do tipo queimação, de intensidade moderada a severa, podendo persistir por anos, e acomete as bordas laterais e a ponta da língua, principalmente. No decorrer do dia, há piora da intensidade dolorosa, acontecendo o mesmo nos estados de tensão, fadiga, ao falar muito, à ingestão de alimentos picantes e quentes, e ocorre melhora com alimentos frios, trabalho e distração (BENSLAMA, 2002; CERCHIARI et al., 2006).

Sua etiologia é largamente variável e de difícil definição, sendo apontados fatores locais, sistêmicos, psicológicos e causas idiopáticas (HUANG et al., 1996). Como geralmente a causa da Síndrome da Boca Ardente é considerada desconhecida, tem sido levantada a hipótese de que a condição estaria relacionada a fatores de ordem psicológica, merecendo destaque a depressão, a ansiedade e o estresse (HAKEBERG; HALLBERG; BERGGREN, 2003). Com relação ao estresse, em estudo realizado por Hakeberg, Hallberg e Berggren (2003), os autores observaram que todas as suas pacientes haviam passado por momentos de grande tensão emocional ou decepção durante suas vidas, culminando com o aparecimento de dor bucal. Assim, sugeriram uma relação entre Síndrome da Boca Ardente e estresse, sendo mais frequente no sexo feminino, da quarta década de vida em diante (CARLSON; MILLER; REID, 2000; NATAH et al., 2004).

\section{Ulceração Aftosa Recorrente}

Condição comum que se caracteriza pelo aparecimento cíclico de lesões ulceradas, únicas ou múltiplas, na mucosa bucal, que apresentam sintomatologia dolorosa (PEREIRA et al., 2006). Fatores como estresse, história familiar, trauma, hipersensibilidade alimentar, deficiências nutricionais, alterações hematológicas e, ainda, um possível envolvimento bacteriano, têm sido propostos como possivelmente relacionados ao aparecimento da doença, porém sua etiologia não tem sido até agora completamente entendida (HEFT; WRA, 1982). O estresse é citado como um fator precipitante e a manifestação clínica das lesões, em muitas das vezes, coincide com períodos de tensão emocional e intenso estado da referida condição emocional. Assim, seu aparecimento pode ser considerado como um tipo de manifestação bucal de doenças psicossomáticas (VICENT; LILLY, 1992; NEVILE et al., 2004).

\section{Herpes Simples Recidivante}

Causada pelo Herpesvirus hominis (HHV), sendo reconhecidos dois tipos imunologicamente distintos: tipo I que envolve quase sempre a parte superior do corpo (região bucal, facial e ocular) e o tipo II que tende a provocar infecções genitais (LOPES et al., 2000). O vírus tem alto poder de contaminação e sua transmissão se dá de forma direta. Após o primeiro contato, o vírus fica em estado de latência, sendo necessário um fator desencadeante como o estresse para sua recorrência (DUTRA et al., 1995). É observada em torno dos quinze anos de idade, manifestando-se inicialmente com desconforto, devido à sensação de ardência, queimação, prurido e depois o aparecimento de numerosas vesículas que se rompem facilmente, causando ulceração, sendo o lábio seu sítio preferencial (VARANDAS, 1997). 


\section{Discussão}

Sabemos que um dos problemas mais comuns que afeta $o$ ser humano é o estresse, o qual culmina num desgaste geral do organismo. Há muitas evidências de que os fatores psicológicos têm um papel importante na etiologia e progressão de muitas doenças, sendo sugerida uma relação entre a existência de desordens emocionais e determinadas condições da cavidade bucal (SAINZ et al., 2001; ESGUEP et al., 1997; ELIAS et al., 2000). Sendo assim, é de fundamental importância o questionamento de como o estresse ou outras alterações psíquicas podem afetar o funcionamento normal do organismo.

A etiopatogenia do líquen plano (SUGERMAN et al., 2002) envolve mecanismos específicos e não específicos, sendo que os primeiros incluem apresentação de antígenos por queratinócitos da camada basal e morte de queratinócitos antígeno-específicos por linfócitos $T$ citotóxicos, enquanto os últimos incluem degranulação dos mastócitos e ativação de metaloproteinases da matriz. Estes mecanismos combinados levariam então ao acúmulo de linfócitos T na lâmina própria subjacente ao epitélio, rompimento da membrana basal, migração de linfócitos $T$ intraepitelial e apoptose dos queratinócitos, achados característicos do líquen plano bucal. Além disso, para estes autores, a cronicidade da doença pode ser explicada em parte por uma deficiência nos mecanismos de imunossupressão mediada pelo fator transformador de crescimento beta (GORSKY et al., 2004).

Várias são as causas que levam ao início deste processo, sendo os distúrbios psicológicos, em particular, níveis exarcebados de estresse e de ansiedade, fatores fortemente associados à doença (SOUSA; ROSA, 2008).

Convém salientar que em situações normais existe um aumento na secreção do hormônio cortisol em resposta ao estresse e que esse hormônio é importante para neutralizar a reação inflamatória, caso contrário, uma ativação do sistema imunológico pode não ser controlada com exatidão e uma reação imune adversa pode ocorrer (STERNBERG; YOUNG; BERNARDINI, 1989). Nos pacientes portadores de líquen plano bucal, os níveis de cortisol são consideravelmente maiores (KORAY et al., 2003).

Apesar de haver evidências indicando que a somatização de desordens psicológicas, como estresse e ansiedade, possam ser apontados como possíveis causas da doença, faltam informações que comprovem, de modo definitivo, tal ligação. Essa discussão também gira em torno da capacidade que os pacientes portadores da doença têm de modular sua resposta imune.

O estresse emocional está presente em grande parte dos pacientes com língua geográfica, sendo este aspecto possivelmente explicado pelo fato de que tanto a mucosa bucal quanto o sistema nervoso têm a mesma origem embrionária ectodérmica, o que poderia explicar a relação causal entre esta condição e o estresse (GONZAGA et al., 1995).

A Síndrome da Boca Ardente pode ser ativada pela composição salivar alterada como consequência da ativação simpática resultante do estresse psicológico, fator este apontado como importante na etiologia da doença (GRUSHKA, 1987). Entretanto, apesar dos pacientes com Síndrome da Boca Ardente poderem apresentar elevado estresse psicológico, em alguns casos, o aparecimento de sintomas dessa síndrome não ter sido relacionado a eventos de vida estressora (ELI, 1994). Apesar de ainda não sido ter consolidado o conhecimento sobre a etiologia da Síndrome da Boca Ardente, de se estabelecer se o estresse é causa ou efeito da doença, é necessário que o cirurgiãodentista deva estar atento não só aos sintomas clínicos da síndrome, uma vez que a normalização psíquica do paciente é fundamental como medida prévia a qualquer tentativa de tratamento.

A etiologia da Ulceração Aftosa Recorrente é amplamente descrita como um processo multifatorial, sendo provável que a existência de uma desregulação do sistema imunológico originada por estresse possa levar ao surgimento da Ulceração Aftosa Recorrente.

É proposto que a Ulceração Aftosa Recorrente seja o resultado da produção anormal de citocinas localizadas na mucosa bucal, associada a um trauma clínico ou subclínico, o que ocasionaria um aumento da intensidade da resposta imunológica celular, devido ao excesso de citocinas, direcionada a áreas focais da mucosa, o que justificaria aspectos autoinflamatórios das lesões (POULTER; LEHNER, 1989; BRUNO et al., 1998)

O aumento de IL-2, responsável pela ativação das células NK, no plasma dos indivíduos com UAR ativa, assim como a sua diminuição nos períodos de remissão podem sugerir um mecanismo de autoimunidade (SUN, 2000). Sugere-se que linfócitos Th3 e a alteração do equilíbrio imunológico entre as respostas celulares podem contribuir para diminuir a tolerância bucal e desencadear uma resposta citotóxica direcionada a antígenos comuns à cavidade bucal e ao epitélio normal, o que favoreceria o aparecimento da Ulceração Aftosa Recorrente (BORRA et al., 2000).

O modelo do Herpes Simples Recidivante tem demonstrado ser excelente para avaliação do papel desencadeado pelo estresse na suscetibilidade a esta doença. A utilização de marcadores imunoneuroendócrinos associados ao Herpes Simples Recidivante mostrou uma diminuição significativa em níveis plasmáticos de células naturais Killer, e em níveis séricos de epinefrina, na semana antecedente ao surgimento da lesão. Desta forma, correlacionamos o papel do estresse como modulador do sistema imune, e sugerimos sua participação como fator desencadeante da doença herpes (LOGAN et al., 1998).

\section{Conclusão}

Com base na literatura pesquisada, podemos sugerir que os aspectos psicossociais, em especial o estresse, têm sua participação na etiologia de algumas condições na cavidade bucal, atuando de forma conjunta com outros fatores. Não está perfeitamente esclarecido o papel do estresse nessas lesões, entretanto, evidências mostram que se abre uma nova perspectiva, tanto na compreensão da etiopatogenia das mesmas como na sua prevenção e no seu manejo clínico. É necessário enfatizar que estas condições devem merecer atenção especial do cirurgião-dentista, que, por sua vez, faz parte de uma equipe multidisciplinar no atendimento do paciente. Encaminhar o paciente portador de uma dessas condições associadas ao estresse a profissionais especializados para uma terapia adjunta pode melhorar sobremaneira o resultado do tratamento odontológico.

\section{Referências}

AMORIM, R. F. B. et al. Líquen Plano Bucal em Pacientes Diabéticos Associado a Carcinoma Mucoepidermóide. Rev. Paul. Odontol., São Paulo, v. 24, n. 4, p. 8-14, 2002.

BASCONES-ILUNDAIN, C. et al. Liquen Plano Bucal (I). Aspectos Clínicos, Etiopatogénicos y Epidemiológicos. Av. Odontoestomatol., Madrid, v. 22, n.1, p. 11-19, enero/feb. 2006.

BENSLAMA, L. Douleurs Bucales. Rev. Prat., Paris, v. 52, p. 400403, 2002.

BORRA, R. C. et al. The Th1/Th2 Immune Type Response of the Recurrent Aphthous Ulceration Analysed by c DNA Microarray. J. Oral Pathol. Med., Copenhagen, v.33, n. 3, p. 140-146, Mar. 2004.

BOUQUOT, M. Reviewing Oral Leukoplakia. Clinical Concepts for the 1990. s. J. Am. Dent. Assoc., Chicago, v. 122, n. 6, p. 80-82, 1991.

BRUNO, I. J. et al. Elevated Levels of Inyterferon Gamma, Tumor Necrosis Factor Alpha, Inteleukins 2, 4 and 5, but not Inteleukin 10, are present in Recurrent Aphthous Stomatitis. Arch. Dermatol., Chicago, v.134, n. 7, p. 827-831, July 1998. 
CARLSON, C. R.; MILLER, C. S.; REID, K. I. Phychosocial Profiles of Patients with Burning Mouth Syndrome. J. Orofacial Pain, Carol Stream, v. 14, n. 1, p. 59-64, Winter 2000.

CERCHIARI, D. F. et al. Síndrome da Boca Ardente: Etiologia Rev. Bras. Otorrinolaringol., São Paulo, v. 72, n. 3, p. 419-424, 2006.

COSTA, L. J. et al. Síndrome da Boca Ardida. Rev. Fac. Odontol. Univ. Fed. Bahia, Salvador, v. 19, p. 56-60, jul./dez. 1999.

DRAGE, L. A.; ROGERS, R. S. Burning Mouth Syndrome. Dermatol. Clin., Philadelphia, v.21, no. 1, p. 135-145, Jan. 2003.

DUTRA, A. T. et al. Infecções pelo Virus Herpes Simplex: Correlações com Outras Patologias. ROBRAC, Goiânia, v. 5, n.16, p. 36-39, dez. 1995.

EDWARDS, P. C.; KELSCH, R. Oral Lichen Planus: Clinical Presentation and Management. J. Can. Dent. Assoc., Otawa, v. 68, n. 8, p. 494-499, 2002.

ELI, I. Antecedents of Burning Mouth Syndrome (glossodymia) - Recent Life Events vs Psychopathologic Aspects. J. Den. Res. Chicago, v.73, n. 2, p. 567-572, Feb.1994.

ELIAS, R. A. et al. Lesões Bucais Associadas ao Estresse. Rev. CRO-RJ, Rio de Janeiro, v. 2, p. 8-14, 2000.

ESGUEP, A. et al. Alteraciones Psicologicas en la Etiopatogenesis de Patologia de la Mucosa Bucal. Rev. Fac. Odont. Univ. Chile, Santiago, v.15, n.2, p. 15-23, jul./dic. 1997.

FEMIANO F. Geographic Tongue (migrant glossitis) and Psoriasis. Minerva Stomatol., Torino, v. 50, no.6, p. 213-218, June 2001.

GARCIA-MEDINA, M.R. Síndrome de la Boca que Arde. Rev. Asoc. Odontol. Argent., Buenos Aires, v. 82, n.2, p. 140-145, 1994.

GONZAGA, H. S. F. et al. Aspectos Epidemiológicos e Etiológicos da Língua Geográfica. Rev. Odontol. UNESP, Marília, v. 24, n.1, p. 169-171, jan./jun.1995.

GORSKY, M. et al. Smoking Habits Among Patients Diagnosed with Oral Lichen Planus. Tob. Induc. Dis., London, v.2, no.2, p. 103-108, June 2004.

GRUSHKA, M. Clinical Features of Burning Mouth Syndrome. Oral Surg. Oral Med. Oral Pathol., St. Louis, v.63, no.1, p. 30-36, Jan.,1987.

HAKEBERG, M.; HALLBERG, L. R. M.; BERGGREN, U. Burning Mouth Syndrome: Experiences from the Perspective of Female Patients. Eur. J. Oral Sci., Copenhagen, v.111, n. 4, p. 305-311, Aug. 2003

HALACK, G. O. C. et al. Liquen Plano: a Importância dos Exames Complementares para o seu Diagnóstico e Tratamento. Rev. Paul. Odontol., São Paulo, ano 26, n.6, p. 15-17, nov./dez. 2004.

HEFT, M.; WRAY, D. Anxiety Levels in Recurrent Aphthous Stomatitis (RAS) Patients. J. Dent. Res., Houston, v.61, p. 264, 1982.

HUANG, W. et al. The Burning Mouth Syndrome. J. Am. Acad. Dermatol., St. Louis, v.34, n. 1, p. 91-98, Jan.1996.

KORAY, M., et al. The Evaluation of Anxiety and Salivary Cortisol Levels in Patientswith Bucal Lichen Planus. Oral Dis., Copenhagen, v.9, no.6, p. 298-301, Nov. 2003.

LAMEY, P. J.; LAMB, A. B. The Usefulness oh the HAD Scale in Assessing Anxiety Mouth Syndrome. Oral Surg. Oral Med. Oral Pathol., St. Louis, v.67, no. 4, p. 390-392, Apr.1989.
LOGAN, H. L. et al. Immune, Stress, and Mood Markers Related to Recurrent Oral Herpes Outbreaks. Oral Surg. Oral Med. Oral Pathol. Oral Radio., St. Louis, v. 86, no.1, p. 48-54, July 1998.

LOPES, F. F. Contribuição ao Estudo da Infecção Herpética na Cavidade Bucal. Rev. Odontol. UNICID, São Paulo,v.12, n.1, p. 77-82, 2000.

LOZADA-NUR, F. Oral Lichen Planus and Oral Cancer: is there Enough Epidemiologic Evidence? Oral Surg. Oral Med. Oral Pathol. Oral Radiol. Endod., St. Louis, v. 89, no. 3, p. 265-266, 2000.

MOLLAOGLU, N. Oral Lichen Planus: a review. Brit. J. Oral Maxillofac. Surg., Edinburg, v. 38, no.4, p. 377, 2000.

NATAH, S. S. et al. Recurrent Aphtous Ulcers Today: a Review of the Growing Knowledge. Int. J. Oral Maxillofac. Surg., Copenhagen, v.33, no. 3, p. 221-234, Apr. 2004.

NEVILE, B. W. et al. Patologia Bucal \& Maxillofacial. 2. ed. Rio de Janeiro: Guanabara Koogan, p. 176-204, 2004.

PEREIRA, K. A. et al. Ulceração Aftosa Recorrente: Revisão dos Conceitos Atuais. Rev. Odontol. UNESP, Marília, v.35, n.1, p. 61-67, jan./mar. 2006.

POULTER, L. W.; LEHNER, T. Immunohistology of Oral Lesions from Patients with Recurrent Oral Ulcers and Behçet's Syndrome. Clin. Exp. Immunol., Oxford, v.78, no. 2, p. 189-195, Nov. 1989.

REGEZI, R.; SCIUBBA, J. A. Patologia bucal: correlações clinicopatológicas. 3.ed. Rio de Janeiro: Guanabara Koogan, p. 27-75, 2000.

RÖDSTROM, P. O. et al. Erosive Oral Lichen Planus and Salivary Cortisol. J. Oral Pathol. Med., Copenhagen, v. 30, no. 5, p. 257-263, May 2001.

SAINZ, B. et al. Stress-associated Immunomodulation and Herpes Simplex Vírus Infecctions. Med. Hypotheses, Edinburgh, v. 56, no.3, p. 348-356, Mar. 2001.

SOTO ARAYA, M.; ROJAS ALCAYAGA, G.; ESGUEP, P. Associación entre Alteraciones Psicológicas y la Presencia de Líquen Plano Bucal, Síndrome Boca Urente y Estomatitis Aftosa Recidivante. Med. Oral Patol. Cir. Bucal, Valencia, v.9, n. 1, p.1-7, enero/feb. 2004.

SOUSA, F. A. C. G.; ROSA, L. E. B. Líquen Plano Bucal: Considerações Clínicas e Histopatológicas. Rev. Bras. Otorrinolaringol., Rio de Janeiro, v. 74, n. 2, p. 284-292, mar./abr. 2008.

STERNBERG, E. M.; YOUNG, W. S. D.; BERNARDINI. R. A Central Nervous System Defect in Biosynthesis of Corticotropinreleasing Hormone in Associated with Susceptibility to Streptococcal Cell Wall-induced Arthritis in Lewis Rats. Proc. Natl. Acad. Sci. USA, Washington, v.86, n.12, p. 4771-4775, June 1989.

SUGERMAN, P. B. et al. The Pathogenesis of Oral Lichen Planus. Crit. Rev. Oral Biol. Med., Boca Raton, v. 13, n.4, p. 350-365, 2002.

SUN, A. et al. Expression of Interleukin-2 Receptor by Activated Peripheral Blood Lymphocytes Upregulated by the Plasma Level of Interleukin-2 in Patients with Recurrent Aphthous Ulcers. Proc. Natl. Sci. Counc. Repub. China B, Taipei, v.24, n.3, p. 116-122, July 2000.

VARANDAS, E. T. Gengivoestomatite Herpética Aguda Primária. Rev. Assoc. Paul. Cir. Dent., São Paulo, v.51, n.1, p. 42-44, jan./fev. 1997.

VICENT, S. D.; LILLY, G. E. Clinical, Historic, and Therapeutic Features of Aphthous Stomatitis. Oral Surg. Oral Med. Oral Pathol., St. Louis, v. 74, n. 1, p. 70-86, July 1992. 